Article de périodique (Journal article)

\begin{abstract}
"Is there a common pathway to behavioral maladjustment for internationally adopted and non-adopted adolescents?"
\end{abstract}

Roskam, Isabelle ; Stiévenart, Marie

\begin{abstract}
The main purpose of the research was to test whether cumulative effects represent a common pathway to behavioral maladjustment for internationally adopted adolescents and controls. The findings of previous comparison and follow-up studies have been contradictory. The hypothesis was tested in an original multi-informant study with 74 adolescents: 40 adoptees and 34 controls. The analyses of the data provided arguments in favor of the existence of a common pathway for adoptees and controls. The accumulation of risk factors in the current characteristics of the adolescents and their family was significantly associated with behavioral outcomes of both adoptees and controls. Implications for research, policy and practice are discussed.
\end{abstract}

Référence bibliographique

Roskam, Isabelle ; Stiévenart, Marie. Is there a common pathway to behavioral maladjustment for internationally adopted and non-adopted adolescents?. In: Journal of Applied Developmental Psychology, (2014)

DOI : 10.1016/j.appdev.2013.12.005 


\title{
Is there a common pathway to maladjustment for internationally adopted and non-adopted adolescents?
}

\author{
Isabelle Roskam*, Marie Stievenart \\ Psychological Sciences Research Institute, University of Louvain, Belgium
}

\section{A R T I C L E I N F O}

\section{Article history:}

Received 29 May 2013

Received in revised form 12 December 2013

Accepted 23 December 2013

Available online $\mathrm{xxxx}$

\section{Keywords:}

Adoption

Cumulative risk

Deprivation

\begin{abstract}
A B S T R A C T
The main purpose of the research was to test whether cumulative effects represent a common pathway to behavioral maladjustment for internationally adopted adolescents and controls. The findings of previous comparison and follow-up studies have been contradictory. The hypothesis was tested in an original multi-informant study with 74 adolescents: 40 adoptees and 34 controls. The analyses of the data provided arguments in favor of the existence of a common pathway for adoptees and controls. The accumulation of risk factors in the current characteristics of the adolescents and their family was significantly associated with behavioral outcomes of both adoptees and controls. Implications for research, policy and practice are discussed.
\end{abstract}

(c) 2014 Elsevier Inc. All rights reserved.
The literature on adoption is vast and rich. One of the major lines of research is comparison studies in which adopted participants are compared with control participants. In this set of studies, the fact of being adopted is considered as a risk factor per se that can lead to significant developmental differences in favor of the control participants. Another major line of research is follow-up studies analyzing the influence of deprivation severity (e.g., age of adoption, pre-adoption abuse or neglect) and other key-risk factors (e.g., age of the biological mother, low birth weight, drug exposure) on behavioral outcomes in adoptees. Because adoption research has been more concerned with outcomes than processes (Palacios, Román, Moreno, \& León, 2009), we found in these two sets of studies contradictory arguments with regard to the main question of the current research, i.e. is there a common pathway to behavioral maladjustment for internationally adopted and nonadopted adolescents? In particular, do cumulative effects constitute a common pathway for this issue? The cumulative effect hypothesis is tested here as a well-known pathway in developmental psychopathology (Cicchetti \& Rogosch, 1996), by considering current adolescent and family factors, i.e. IQ, attachment and parenting, and their cumulative effect on behavioral maladjustment. After a presentation of the cumulative effect hypothesis, arguments in favor of a negative answer to the main question will be presented first before others supporting a positive answer are outlined. These arguments will lead to two opposite sets of hypotheses that will be tested in an original multi-informant study with 74 adolescents, 40 adoptees and 34 controls. The implications for clinical and the social policy of each set of hypotheses will be proposed and discussed.

\footnotetext{
* Corresponding author.

E-mail address: isabelle.roskam@uclouvain.be (I. Roskam).
}

\section{The cumulative effect hypothesis}

Whereas the vast majority of empirical studies of adolescents' behavioral maladjustment have considered adolescent or family risk factors in isolation, multiple risk studies address the importance of considering several frameworks in combination. One of the most interesting hypotheses coming from the multiple risk studies is that of the cumulative effect. It posits that the accumulation of risk factors, even regardless of their content, can be considered as a pathway to maladjustment, and that its influence is greater than that of any factor in isolation (Cicchetti \& Rogosch, 1996). Hence, a single risk factor may not be enough to derail behavioral adjustment, but the accumulation of multiple risks will be deleterious (Greenberg, Speltz, DeKlyen, \& Jones, 2001). Multiple risk studies have traditionally focused on the association between a general outcome such as academic achievement, adaptive or maladaptive functioning or behavioral issues on the one hand, and on the other hand several specific risks across several ecological levels, i.e. the participant's personal characteristics, family, school, peer and neighborhood factors. Such a pathway of accumulation of multiple risks has been tested in several studies with community-sample or referred subjects, demonstrating a significant linear relation between the cumulative risk index, computed by summing the number of dichotomized risk factors such as high vs. low IQ, secure vs. insecure attachment, or good vs. poor parenting for example, and children's or adolescents' externalizing or internalizing behavior (Appleyard, Egeland, van Dulmen, \& Sroufe, 2005; Atzaba-Poria, Pike, \& Deater-Deckard, 2004; Gerard \& Buehler, 2004; Greenberg et al., 2001; Lanza, Rhodes, Nix, \& Greenberg, 2010; Lucio, Rapp-Paglicci, \& Rowe, 2011; Roskam, Meunier, Stievenart, \& Noël, 2013; Trentacosta et al., 2008). Some of these studies were cross-sectional like the present one, and therefore unable to address the core question of the directionality of the effects (e.g., Atzaba-Poria 
et al., 2004; Greenberg et al., 2001). Rather they contributed to documenting the association between multiple specific risks which are combined together and general issues. Others were based on a longitudinal design in which the accumulation of risks preceded the general outcome (e.g., Gerard \& Buehler, 2004; Lanza et al., 2010; Roskam, Meunier et al., 2013; Roskam, Stievenart et al., 2014). The cumulative risk hypothesis has also been tested in follow-up studies of adoptees by considering the history of maltreatment and deprivation for the computation of the risk index (Kriebel \& Wentzel, 2011); to the best of our knowledge, however, it has never been tested by considering the current characteristics of the adoptee and his/her post-adoption environment.

Adopted adolescents follow a different pathway to behavioral maladjustment than controls

The adoptive status is assumed to harm later development (van der Vegt et al., 2009). Comparison studies rely on such an assumption and consider the adoptive status as a risk factor per se. Significant differences were therefore expected in studies in which behavioral issues of adoptees were compared with those of controls. The results from previous comparative studies conducted in community samples mainly led to the conclusion that significant differences were found between adoptees and control participants with regard to behavioral adjustment (Dalen \& Rygvold, 2006; Dhavale, Bhagat, \& Thakkar, 2005; Hawk \& McCall, 2010). A meta-analysis of 98 adoptee-control studies concluded that adoptees displayed higher average levels of both externalizing and internalizing behavior than controls (Juffer \& van IJzendoorn, 2005). Also, compared with their non-adopted siblings, adoptees' behavioral adjustment was worse in late adolescence (Weinberg, Waldman, van Dulmen, \& Scarr, 2004). Adoptees have also been shown to be overrepresented in the mental health population (Hjern, Lindblad, \& Vinnerljung, 2002; Weiss, 1985). In sum, the results from many comparative studies have led to the conclusion that adoptees tend to be less well-adjusted than controls. The results of several followup studies have supported this conclusion by demonstrating the influence of pre-adoption social and emotional adversity on behavioral adjustment (Gagnon-Oosterwaal et al., 2012a,b; Merz \& McCall, 2010; Simmel, Brooks, Barth, \& Hinshaw, 2001; Xing Tan \& Marfo, 2006).

Another argument in favor of a negative answer to our main question is that several symptoms, especially inattention and overactivity, have recently been thought to form a specific institutional deprivation syndrome. ADHD has been considered by several authors as a characteristic outcome of early deprivation (Kreppner et al., 2001; Roskam et al., 2014; Rutter et al., 2007b; Sonuga-Barke \& Rubia, 2008). If the hypothesis of specific psychological issues for adoptees is confirmed, that of a common pathway to behavioral maladjustment for adoptees and controls will be invalidated.

In line with these arguments, it may be considered that the behavioral issues of adoptees are especially explained by their status which could also lead to a higher risk of low IQ (Behen, Helder, Rothermel, Solomon, \& Chugani, 2008; Miller, Chan, Tirella, \& Perrin, 2009), insecure attachment (Palacios et al., 2009; Rutter et al., 2007b; van den Dries, Juffer, van Ijzendoorn, \& Bakermans-Kranenburg, 2009), and poor parenting and stress in the adopting family (Gagnon-Oosterwaal et al., 2012b; Judge, 2003; Palacios et al., 2009; Rijk, Hoksbergen, ter Laak, van Dijkum, \& Robbroeckx, 2006; Sánchez-Sandoval \& Palacios, 2012), leading to a higher cumulative score on average in adoptees than controls. In other words, by contrast with the cumulative effect hypothesis, adoptive status as a risk factor in isolation is held to be sufficient to derail adoptees' behavior. Adoptees therefore constitute a specific group of adolescents. The pathway leading them to maladjustment, it is argued, should depend to a large degree on their preadoption history (Kriebel \& Wentzel, 2011), greater genetic vulnerability (Kendler et al., 2012; Siira, Wahlberg, Miettunen, Tienari, \& Làksy,
2006), institutional deprivation (Sonuga-Barke \& Rubia, 2008) or even their inner psychological struggle as they begin to comprehend their adoptive status (Brodzinsky, 2011; Brodzinsky, Singer, \& Braff, 1984; Palacios \& Brodzinsky, 2010). They therefore have special needs in comparison with control adolescents, and specific prevention and treatment measures should be proposed to address their behavioral issues. The hypotheses following from these arguments are as follows. First, significant differences are expected between adoptees and controls, with higher behavioral maladaptation and a higher cumulative risk factor score for adoptees than controls. Second, with regard to the prediction of behavioral maladjustment, there will be no main cumulative effect of risk factors resulting from IQ, attachment and parenting. Rather, a significant interaction between group affiliation (adoptees vs. controls) and cumulative effect will be found, meaning that cumulative effect operates in different ways in the two subsamples.

There is a common pathway to behavioral maladjustment for adopted and non-adopted adolescents

A first argument for a positive answer to our main question is that existing findings have pointed to significant differences in behavioral adaptation between adoptees and controls, with the results unexpectedly in favor of adoptees (Christoffersen, 2012; Tan \& Marfo, 2006). Also, in comparison studies in which significant differences to the disadvantage of adoptees were found in behavioral adaptation, the effect sizes were low (Bimmel, Juffer, van Ijzendoorn, \& BakermansKranenburg, 2003; Juffer \& van IJzendoorn, 2005), suggesting first that variations in behavioral adjustment stay in the normal range (Dalen \& Rygvold, 2006), and second that although adoptees display more behavior problems than their non-adopted counterparts, this concerns a minority of adoptees. The large majority function well, and much better than might be expected based on their background of deprivation (Juffer \& van IJzendoorn, 2005). It is therefore assumed that the effects of adoptive status can be modified by a favorable post-adoption environment (Goldman \& Ryan, 2011; Kriebel \& Wentzel, 2011; Lindblad, Weitoft, \& Hjern, 2010; Whitten \& Weaver, 2010). It can also be assumed that differences between adoptees and controls are attributable to inter-individual differences rather than to group differences, because of the heterogeneity of the internationally adopted population (Lindblad et al., 2010; Weinberg et al., 2004). Furthermore, the overrepresentation of adoptees in the mental health population can be explained to some extent first by the greater attention that adopting parents give to the symptoms of their adopted child, whom they consider to be at greater risk than biological offspring, and second by the fact that adopting parents tend to be better educated with higher household incomes than biological parents (Weinberg et al., 2004).

A second argument is that follow-up studies of adoptees most often focus on the influence of pre-adoption key risk factors rather than on the influence of the characteristics of the adoptee and his/her postadoption environment on behavioral adjustment (Goldman \& Ryan, 2011). Therefore, we cannot rule out the possibility that the influence of the adolescent's current characteristics and the protective environment provided by the adoptive family is so important that over and above their adoptive status, adolescents follow the same pathway to behavioral adjustment as controls. In line with the cumulative effect hypothesis, the influence of adoptive status considered in isolation will not be enough to derail behavioral outcomes. Moreover, such a status could not lead to a higher risk of low IQ, insecure attachment and poor parenting in the adoptive family (Dhavale et al., 2005), which means that there will be a similar cumulative score on average in adoptees as in controls.

In line with these arguments, it can be thought that the behavioral issues of adoptees are only explained to a slight extent by the fact of having been adopted. The adoptive family provides a protective environment which outweighs the influence of their adoptive status, leading adoptees to follow a pathway to behavioral adjustment similar to that of 
any other adolescent. Their needs are to some extent similar to those of control adolescents, and similar prevention and treatment measures should be proposed to address their behavioral issues. The hypotheses following from these arguments are as follows. First, non-significant differences are expected between adoptees and controls with similar behavioral adaptation, IQ attachment, parenting and cumulative scores in the two subsamples. Second, with regard to the prediction of behavioral adjustment, a main effect of the cumulative score resulting from risk in IQ attachment and parenting is expected to be confirmed. In addition, no interaction will be found between group affiliation (adoptees vs. controls) and the cumulative risk score, meaning that cumulative risk operates in the same way in the two subsamples.

\section{The current study}

In sum, the main purpose of the current research is to test whether cumulative effects represent a common pathway to behavioral maladjustment for internationally adopted adolescents and controls. The cumulative hypothesis is tested in a multi-informant study by considering IQ attachment and parenting, and their cumulative effect on behavioral maladjustment among 74 adolescents, 40 adoptees and 34 controls.

\section{Method}

Sample

This study is part of the Attachment Adolescents Research Network (AAARN). Data were collected from 74 adolescents, 40 adoptees and 34 controls, and their parents. Both adoptive and control families were from the French-speaking part of Belgium. These families were informed about the research project by social networks or by word of mouth. All the families that voluntarily contacted the research team with a view to participating within the six-month period set for this project and that satisfied the inclusion criteria were included. Each child came from a different family.

The data collection was first completed in the adoptee subsample. For the current research, the inclusion criteria for adoptees were that the child had been adopted before the age of seven years, i.e. a maximum of 84 months, that they were aged 11 to 16 years, and that they knew they had been adopted. The mean age of adoption was
16.12 months $(s d=15.98)$; time in adoptive family ranged from 6.92 to 16 years and was 12.51 years $(s d=2.17)$ on average. Adoptees came from 13 different countries: 11 from Vietnam (14.9\%), 6 from Brazil (8.1\%), 5 from Ethiopia (6.8\%), 3 from China, Colombia and Haiti (4.1\% each), 2 from Belgium and Romania (2.7\% each) and 1 from Cape-Verde, Guatemala, Madagascar, Thailand and Ukraine (1.4\% each). In a second step, data collection was conducted among control families, which were strictly matched with the characteristics of the adoptee subsample, i.e. adoptees' age and sex, parents' educational level and marital status and number of siblings. The socio-demographic characteristics of the two subsamples are presented in Table 1 with the results of the statistical comparisons. No significant difference was displayed between the two subsamples.

Eight trained master's students visited the parents and adolescents at home in order to describe the study. They gave instructions on completing the instruments and administered the IQ tasks to the adolescents.

\section{Outcome measures}

The behavioral maladjustment of the adolescents was assessed with the externalizing and internalizing behavior scales of the Child Behavior Checklist (CBCL) covering ages 6-18 years (Achenbach \& Rescorla, 2001). The externalizing behavior (EB) scale encompasses the rulebreaking and aggressive behavior syndrome scales. The internalizing behavior (IB) scale encompasses the anxious/depressed, somatic complaints and withdrawn syndrome scales. The two scales were completed both by the adolescents with the self-report form and by their parents. The data were checked for normality. In order to control for the shared-method variance bias, to reduce the measurement error (Cole \& Maxwell, 2003) and to limit the number of variables in the present study with its modest sample size, we used a cross-rater strategy by averaging the adolescent's and the parents' $\mathrm{EB}, r(72)=.59$, $p<.001$, and IB scores, $r(72)=.41, p<.001$, although the inter-rater correlations were only moderate. Note that these moderate correlations were in the same range or even higher than in previous cross-informant studies, where the parent-youth agreement was .25 on average (Achenbach, McConaughy, \& Howell, 1987) and more recently .44 for EB and .41 for IB (Rescorla et al., 2013).

Table 1

Socio-demographic characteristics of the two subsamples and statistical comparisons.

\begin{tabular}{|c|c|c|c|}
\hline & Adoptees & Controls & \\
\hline & $N=40$ & $N=34$ & Statistics \\
\hline Adolescents' age & $M=13.15(s d=1.88)$ & $M=13.35(s d=1.93)$ & $t(72)=-.45, p>.10$ \\
\hline Sex (\%boys) & $55 \%$ & $55.8 \%$ & $\chi^{2}(1)=.00, p>.10$ \\
\hline \multicolumn{4}{|l|}{ Educational level } \\
\hline \multicolumn{4}{|l|}{ Mothers } \\
\hline Elementary school & $0 \%$ & $0 \%$ & \\
\hline Secondary school & $25 \%$ & $8.8 \%$ & \\
\hline Undergraduate studies & $47.5 \%$ & $52.9 \%$ & $\chi^{2}(4)=5.05, p>.10$ \\
\hline Graduate studies & $5 \%$ & $11.8 \%$ & \\
\hline Post-graduate studies & $22.5 \%$ & $26.5 \%$ & \\
\hline \multicolumn{4}{|l|}{ Fathers } \\
\hline Elementary school & $7.5 \%$ & $2.9 \%$ & \\
\hline Secondary school & $17.5 \%$ & $23.5 \%$ & \\
\hline Undergraduate studies & $40 \%$ & $35.3 \%$ & $\chi^{2}(3)=4.00, p>.10$ \\
\hline Graduate studies & $10 \%$ & $0 \%$ & \\
\hline Post-graduate studies & $22.5 \%$ & $38.3 \%$ & \\
\hline Marital status (\% separated) & $12.5 \%$ & $8.8 \%$ & $\chi^{2}(2)=.29, p>.10$ \\
\hline \multicolumn{4}{|l|}{ Number of siblings } \\
\hline 1 & $12.5 \%$ & $8.8 \%$ & \\
\hline 2 & $30 \%$ & $32.3 \%$ & \\
\hline 3 & $40 \%$ & $35.5 \%$ & $\chi^{2}(4)=.97, p>.10$ \\
\hline 4 & $15 \%$ & $17.6 \%$ & \\
\hline 5 & $2.5 \%$ & $5.8 \%$ & \\
\hline
\end{tabular}




\section{Risk factor measures}

IQ

An evaluation of IQ was carried out using four subtests of the WISCIV (Wechsler, 2005): Similarities, Matrix Reasoning, Letter-Number Sequencing and the Symbol Search. The standardized scores of the four subtests were correlated to each other with a coefficient ranging from $r(72)=.23, p<.05$ to $r(72)=.61, p<.001$. The mean of the standardized scores of the four subtests was used in the analyses.

\section{Attachment}

The adolescent's attachment was assessed by means of the questionnaire "Experiences in Close Relationships Questionnaire - Revised" (ECR-R; Brennan, Clark, \& Shaver, 1998; Fraley, Waller, \& Brennan, 2000). This questionnaire consists of two subscales (18 items each): Anxiety (e.g., "I worry about being abandoned") and Avoidance (e.g., "I prefer not to show a partner how I feel deep down"). A 5-point Likert-type scale $(1=$ completely disagree and $5=$ completely agree $)$ was provided. The ECR-R has been used in many studies since 1998 and has been found to be highly reliable and to have high construct and predictive validity (Shaver, Mikulincer, \& Fraley, 2002; Sibley \& Liu, 2004). Latent variable path analyses showed that longitudinal measures of both the anxiety and avoidance subscales were remarkably stable over a 6-week assessment period (86\% shared variance over time), which suggests that the ECR-R provides stability estimates of trait attachment that are largely free from measurement error over short periods of time (Sibley \& Liu, 2004). Finally, Cronbach's alphas were initially .91 for Anxiety and .94 for Avoidance (Brennan et al., 1998). Because the two subscales were strongly correlated with $r(72)=.74$, a mean score was computed and used in the analyses.

\section{Parenting}

Parenting behavior was assessed both by the adolescents and by the parents themselves. Parenting behavior was assessed with two versions of the EPEP scale (Meunier \& Roskam, 2007). The first version was a selfreport about the parents' own parenting behavior. It was a 35-item instrument yielding nine factors: positive parenting, monitoring, rules, discipline, inconsistent discipline, harsh punishment, ignoring, material rewarding, and autonomy. A 5-point Likert-type scale was provided for each item, ranging from never to always. Recently validated on 493 mothers and fathers of developing normally children, the EPEP scale has good psychometric properties. Cronbach's $\alpha$ ranged from .65 to .89; the total percentage of variance explained by the nine factors was 64.3\%; test/retest correlations for a sample of 45 parents varied between $r(43)=.51$ and .84 . Confirmatory factor analyses showed that two second-order factors covering the supportive and controlling dimensions of parenting emerged from the initial factor solution. The supportive factor was composed of positive parenting, autonomy, monitoring, and rules, and included items such as "When my child has a problem, we look together at different possible solutions." The controlling factor included discipline, harsh punishment, material rewarding, inconsistent discipline, and ignoring, and included items such as "When my child doesn't obey a rule, I sometimes threaten to punish him or her, but in the end I don't carry out the threat." The fit measures demonstrated an acceptable fit to the data, with goodness of fit index (GFI) $=0.92$ and root mean square residual $(\mathrm{RMR})=0.04$, although the root mean square error of approximation (RMSEA) was only 0.11 (Hu \& Bentler, 1999). All the estimated factor loadings were significant (Meunier \& Roskam, 2007).

The second version was designed for children and adolescents assessing the childrearing behavior they received from their parents. It was a 30 -item instrument yielding the same nine factors and similar 5-point Likert-type scales. It has been validated among 159 8-to-14year-old children and 834 13-to-18-year-old adolescents and found to display good psychometric properties (Meunier \& Roskam, 2007). The analysis supported the relevance of the nine-factor solution. The amount of variance explained was $62.04 \%$ for the children, $62.60 \%$ for the adolescents, and $61.74 \%$ for the two groups taken together. The correlations suggested the same second-order solution for young people as for parents. A CFA was conducted based on the covariance matrix and using maximum likelihood estimation. Although the $\chi^{2}$ statistic was significant, $\chi^{2}(26)=394.3, p<.001$, other fit measures demonstrated an acceptable fit to the data. The indices were similar to those for parents: $G F I=0.91, \quad$ RMSEA $=0.10, \quad R M R=0.07$ for children; GFI $=0.92$, RMSEA $=0.12$, RMR $=0.07$ for adolescents; and GFI $=$ 0.92 , RMSEA $=0.12$, RMR $=0.06$ for children and adolescents together. The completely standardized factor loadings for the pooled sample (children and adolescents) mostly ranged between .40 and .60; error variances ranged between .23 and .88 . The two dimensions had almost zero correlations. For both versions, in order to reduce the number of constructs in the current study, the second-order factors of the EPEP scale, i.e. support and control, were used in the analyses. In order to control for the shared-method variance bias, to reduce the measurement error (Cole \& Maxwell, 2003) and to limit the number of variables in the present study with its modest sample size, we used a cross-rater strategy by averaging the adolescent's and parents' support, $r(72)=.34, p<.01$, and control, $r(72)=.43, p<.001$, scores although the inter-rater correlations were only moderate. Note that these moderate correlations were in line with previous cross-informant correlations, where the parent-youth agreement ranged between $r(991)=.21$ and .62 (Meunier \& Roskam, 2007).

\section{Analysis strategy}

Prior to the main statistical analyses, the cumulative score was computed in order to test the hypotheses. A dichotomous score, i.e. high vs. low risk, was computed in each of the three factors. High-risk was defined as a score in the lower third (for IQ and parenting support) or in the higher third (for anxious/avoidant attachment and parenting control) of the distributions in the whole sample. Those who were in the target one-third of the distribution in the sample were considered as incurring the risk factor, the others as safe. A cumulative score was finally computed for each child by adding together the dichotomous (0-1) scores in each of the factors under consideration. The cumulative score finally ranged from 0 to 4 .

As a preliminary analysis, the pattern of correlations between the outcomes (EB, IB) and the risk factors (IQ attachment and parenting support and control) was studied in the two subsamples. In order to test the hypothesis of group-related differences, one-way ANOVAs were computed to establish whether there were mean differences between adoptees and controls in the outcomes, i.e. EB and IB, the risk factors, i.e. IQ attachment, supportive and controlling parenting, and the cumulative score. In order to test the main cumulative effect hypothesis, the two outcomes were considered separately in linear stepwise regression models in which age and sex were controlled for in a first step, group affiliation (adoptees vs. controls) was entered in a second step, the cumulative score was entered in a third step, and the interaction between the cumulative score and group affiliation was added in a last step. A power analysis for the multiple regression model with a tail of 1 , an expected effect size of .15, an error probability of .05, and five predictors in the model (sex, age, group affiliation, cumulative score, cumulative score* group affiliation) was conducted with GPower 3.1.7. (Faul, Erdfelder, Buchner, \& Lang, 2009; Faul, Erdfelder, Lang, \& Buchner, 2007). The sample size that was recommended was $N=74$.

\section{Results}

\section{Preliminary analysis}

Correlations between the outcomes and the risk factors within the two subsamples are shown in Table 2. With regard to the outcomes, the results show that the comorbidity between EB and IB was significantly higher among the adoptees than among the 
Table 2

Correlations between outcomes and risk factors among adoptees and controls.

\begin{tabular}{|c|c|c|c|c|c|c|}
\hline & $\mathrm{EB}$ & IB & IQ & Attachment & Parenting support & Parenting control \\
\hline EB & - & $.66^{* * *}$ & -.07 & $.28^{\dagger}$ & -.16 & .20 \\
\hline IB & .19 & - & -.21 & .07 & -.02 & .22 \\
\hline IQ & $-.54^{* * *}$ & .10 & - & $-.32^{*}$ & .11 & $-.51^{* * *}$ \\
\hline Attachment & $.40^{*}$ & .24 & -.05 & - & .20 & .12 \\
\hline Parenting support & $-.34^{*}$ & $-.30^{\dagger}$ & .18 & -.05 & - & .19 \\
\hline Parenting control & .00 & -.03 & .12 & .02 & .18 & - \\
\hline
\end{tabular}

Note: Coefficients above the diagonal are for adoptees; those under are for controls.

${ }^{\dagger} p<.10{ }^{*} p<.05 .{ }^{* * *} p<.001$.

controls, $Z(1)=-2.43, p<.01$. In terms of the relations between the risk factors the associations between attachment and the other factors, although not significantly different, were more systematic among the adoptees, with $r(38)$ of .12 for parenting control, .20 for parenting support and -.32 for IQ, than among the controls, with $r(32)$ from -.05 for IQ and parenting support to .02 for parenting control. A strong negative correlation of $r(38)=-.51$ between IQ and parenting control was also displayed for adoptees, whereas the relation was significantly lower in controls, with $r(32)$ of .12, $Z(1)=-1.83, p<.05$. The risk factors were seen to be independent from each other among controls, with absolute coefficients ranging from $r(32)=.02$ to .18 , but less independent from each other among adoptees, with coefficients ranging from $r(38)=.11$ to .51 . Finally, the patterns of relations between the outcomes and the risk factors also revealed several differences between the two subsamples. In controls, EB was significantly associated with anxious-avoidant attachment, $r(32)=.40, p<.05$, low IQ, $r(32)=$ $-.54, p<.001$, and lack of parenting support, $r(32)=-.34$, $p<.05$. The same was not true for adoptees, whose EB only tended to relate to anxious-avoidant attachment, $r(38)=.27, p<.10$. The comparison of the correlation coefficients confirmed that the association between EB and IQ was significantly stronger in controls than in adoptees, $Z(1)=-2.17, p<.05$. Also, IB in controls tended to be related to lack of parenting support, $r(32)=-.30, p<.10$, but not in adoptees.

Besides its relevance for considering the two groups of participants, the pattern of correlations was also useful for checking the validity of the measures in the samples. For example, the low coefficients that were shown between IB and attachment, $r(38)=.07, p>.10$ and $r(32)=.24, p>.10$, confirmed that the two constructs were not confused: the first one measured the general issue of behavioral maladjustment, whereas the second one measured a specific aspect of the adolescents' personal characteristics.

\section{Group-related differences}

The comparison between the two subsamples with one-way ANOVAs revealed one significant difference. EB was higher in adoptees than controls, with a medium effect size of .54 (Cohen, 1988). However, the two groups were not different with respect to IB, attachment, IQ parenting support and control or cumulative score. Note that in the adoptee subsample, $60 \%$ of the adolescents were in the normal range, $20 \%$ in the clinical range and $20 \%$ in the middle both for EB and IB. In the control subsample, $88.2 / 76.5 \%$ of the adolescents were in the normal range, 5.9/8.8\% in the clinical range and 5.9/14.7\% in the middle for EB and IB respectively. Descriptive statistics and one-way ANOVAs comparing adoptees and controls are presented in Table 3.

\section{The cumulative effect hypothesis}

The stepwise regression analyses enabled us to test our main question of a common pathway to behavioral adaptation for adoptees and controls. With age and sex being controlled for, a significant effect of group affiliation was found for EB but not for IB, which replicated the results from the comparison between the two subsamples. A main effect of the cumulative score was also found for the two outcomes. The cumulative effect explained an additional amount of variance of $15 \%$ for EB and of $6 \%$ for IB. However, no significant relation was displayed between the interaction term and the outcomes, suggesting that the cumulative score operates in the same way in the two subsamples. The results of the regression analyses are presented in Table 4.

\section{Discussion}

The main purpose of the current research was to test whether there was a common pathway to behavioral maladjustment for adopted and non-adopted adolescents. The cumulative effect hypothesis was tested as a possible common pathway leading to EB and IB in adolescence. Because contradictory arguments had been found in previous comparison and follow-up studies, two opposite sets of hypotheses were formed. The analyses of the data collected from 74 adolescents, 40 adoptees and 34 controls provided arguments leading us to conclude mainly in favor of a positive answer to the main question of the research, but also to recognize that the results provide a nuanced picture.

Only one difference was found in the comparison between the adoptees and the controls. Adoptees had higher scores for EB than their counterparts, with a medium effect size. However, no significant differences were displayed either for IB or for the risk factors. Adoptees were on average not at higher risk of lower IQ higher anxious/avoidant

Table 3

Descriptive statistics for adoptees and controls and one-way ANOVAs.

\begin{tabular}{|c|c|c|c|c|c|c|c|c|}
\hline & \multicolumn{3}{|c|}{ Adoptees } & \multicolumn{3}{|c|}{ Controls } & \multirow[b]{3}{*}{$F(1,72)$} & \multirow[b]{3}{*}{$d$} \\
\hline & \multicolumn{3}{|c|}{$N=40$} & \multicolumn{3}{|c|}{$N=34$} & & \\
\hline & $M$ & $s d$ & Range & $M$ & $s d$ & Range & & \\
\hline EB & 11.72 & 7.01 & $3.00-33.5$ & 8.57 & 4.65 & $2.00-22.00$ & $4.99^{*}$ & .54 \\
\hline IB & 10.53 & 6.30 & $2.00-31.00$ & 8.64 & 4.36 & $2.50-19.50$ & 2.17 & \\
\hline IQ & 9.83 & 2.65 & $2.00-14.00$ & 10.24 & 2.33 & $4.75-14.00$ & 0.40 & \\
\hline Attachment & 3.49 & 0.80 & $1.69-5.50$ & 3.75 & 0.61 & $2.36-5.11$ & 2.37 & \\
\hline Parenting support & 3.91 & 0.42 & $3.01-4.69$ & 4.02 & 0.35 & $3.18-4.94$ & 1.30 & \\
\hline Parenting control & 2.15 & 0.49 & $1.22-3.19$ & 2.12 & 0.61 & $1.04-3.53$ & 0.06 & \\
\hline Cumulative score & 1.75 & 1.03 & $0-4$ & 1.71 & 1.06 & $0-4$ & 0.03 & \\
\hline
\end{tabular}

$* p<.05$. 
Table 4

Stepwise regression analysis predicting behavioral maladjustment.

\begin{tabular}{llrr}
\hline & & EB & IB \\
& & $\beta$ & $\beta$ \\
\hline Step 1 & Age & .09 & -.08 \\
& Sex & -.11 & .13 \\
$\mathrm{R}^{2}$ & & .02 & .03 \\
Step 2 & Age & .10 & -.08 \\
& Sex & -.11 & .13 \\
& Group affiliation & $-.26^{*}$ & -.16 \\
$\mathrm{R}^{2}$ & & $.07^{*}$ & .03 \\
Step 3 & Age & .13 & -.05 \\
& Sex & -.03 & .19 \\
& Group affiliation & $-.25^{*}$ & -.16 \\
& Cumulative score & $.39^{* * *}$ & $.26^{*}$ \\
$\mathrm{R}^{2}$ & & $.15^{* * *}$ & $.06^{*}$ \\
Step 4 & Age & .13 & -.05 \\
& Sex & -.03 & .19 \\
& Group affiliation & $-.25^{*}$ & -.16 \\
& Cumulative score & .20 & .38 \\
& Cumulative score $\times$ Group affiliation & .19 & -.12 \\
$\mathrm{R}^{2}$ & & .00 & .00 \\
Total $\mathrm{R}^{2}$ & & .24 & .12 \\
\hline
\end{tabular}

Note: $\beta$ are standardized coefficients

${ }^{*} p<.05^{* * *} p<.001$.

attachment, less supportive and more controlling parenting than controls. In other words, it can be suggested that adoptive status seems to be enough to lead to high risk in behavioral maladjustment, but only for EB. Nevertheless, in line with the predictions from the cumulative effect hypothesis, a single factor in isolation, such as adoptive status, is not enough to have an adverse effect in other areas such as IB, IQ attachment, and parenting. Furthermore, the significant differences in EB but not in IB can be interpreted in line with recent research, which points to externalized rather than internalized symptoms as specific affective deprivation symptoms (Kreppner et al., 2001; Roskam et al., 2014).

The same positive answer to the main question was further supported by the regression analysis. The relevance of the cumulative effect was confirmed as a main effect irrespective of group affiliation: after controlling for age, sex, and group affiliation, the cumulative score predicted an additional part of the variance in EB (15\%) and in IB (6\%). The interaction term (step 4) was also not significant, and led to zero change in $R$-square. In other words, the cumulative effect of current risk factors can, as expected, be considered as a significant pathway to behavioral maladjustment both in adoptees and in controls.

In contrast with the arguments in favor of the positive answer to the main question of the research, the pattern of correlations revealed several specific characteristics of the two subsamples. The interrelations between the variables under consideration were seen to differ between controls and adoptees. For controls, the pattern of correlations both between the outcomes and the risk factors as well as among the risk factors fits more clearly with general expectations from previous research, but not so or only to a lesser extent for adoptees. With regard to the relations between the outcomes and the risk factors among controls, EB was associated with low IQ $r(32)=-.54$, anxious-avoidant attachment, $r(32)=.40$, and low support in parenting, $r(32)=-.34$. IB was also associated with low parenting support, $r(32)=-.30$. For adoptees, however, apart from the relation between EB and attachment, $r(38)=.28$, the pattern of correlations displayed no association between the outcomes and the risk factors. With regard to the risk factors, they were found to be independent among controls, with $r(32)$ ranging from .02 to .18 , but related to each other to a greater extent among adoptees, with $r$ (38) ranging from .11 to .51 . The specific pattern of correlations in the adoptee subsample suggests that this group is a mixed bag, with a wider range of data and higher standard deviations than controls at least for outcomes (see Table 2), and also a less coherent pattern of correlations. Such heterogeneity in the adoptee subsample could be due to the diversity of countries of origin, the effect of which has been shown in previous work due to differing health systems and care services (Roskam et al., 2014). The heterogeneity of the adoptee population has been stressed in previous research, and it consequently constitutes an important limitation for the interpretation of the findings (Lindblad et al., 2010; Weinberg et al., 2004).

With regard to the comorbidity between EB and IB, a surprisingly low correlation was found among controls, $r(32)=.19$, and a high comorbidity, $r(38)=.66$, was found for adoptees. The comorbidity displayed for adoptees is close to the moderate to high coefficients usually reported in previous research conducted with adolescents in clinical and non-clinical samples (McConaughy \& Achenbach, 1994; McConaughy \& Skiba, 1994; Oland \& Shaw, 2005; Zahn-Waxler, Klimes, \& Slattery, 2000). On the contrary, the EB-IB comorbidity of $r(32)=.19$ found among controls is very unusual. It can be explained by the unusual multi-informant scores that were computed by averaging parents' and adolescents' reports. In fact, the EB-IB comorbidity found for control parents was $r(32)=.41$, which is close to coefficients from previous research. However, the EB-IB comorbidity found for control adolescents was only $r(32)=.15$, which is actually low. The computation of a multi-informant score led to the low $r(32)=.19$ coefficient. In line with a recent study, EB-IB correlations could be explained by informant-specific factors, and the results support the idea that using only a single informant and a single instrument can easily result in overestimation of EB-IB correlations (Noordhof, Oldehinkel, Verhulst, \& Ormel, 2008).

Our results give in sum a plausible explanation of why adoptees have both common and special needs in comparison with control adolescents. On the one hand, adoptees have been seen to be at higher risk of EB and to display a specific pattern of inter-correlations in comparison with controls. On the other hand, a main effect of the cumulative score has been found, irrespective of the subsample under consideration. With regard to the main conclusion that the research question can be answered affirmatively, the point is not to deny the specific influence of adoptive status, but rather to illustrate that when its influence is controlled for, adopted adolescents follow a similar developmental pathway to that of any other adolescent with regard to behavioral issues. The cumulative effect of current individual and family risk factors appears to be a good theory both for adolescents who have had the unusual experience of adoption as well as for those who have been reared by their biological parents. These results are encouraging because they show that adoptive families play an effective role as a protective environment which outweighs the influence of adoptive status by placing the adopted adolescents on the same developmental pathways as controls.

As a consequence for clinical intervention and policy issues, nuanced recommendations can be proposed. In particular, the relevance of considering the accumulation of risk factors in their current characteristics and their family features has been proved. However, specific attention should be given to adoptees' propensity to display externalizing symptoms, which could be a characteristic outcome of early deprivation (Kreppner et al., 2001; Roskam et al., 2014; Rutter et al., 2007a; Sonuga-Barke \& Rubia, 2008), to the specific high rate of EB and IB comorbidity, and to the higher interdependence between the risk factors. In sum, the results of the current study illustrate the interplay between adoptive status, current personal characteristics and adopting family features. In some situations, the interaction between these will result in an exacerbation of difficulties. But in the vast majority of cases, adoption is a positive intervention carried out by adopters who have been selected and have above-average commitment to the task. The absence of significant differences between controls and adoptees in attachment and parenting measures could be understood in this context.

Although important from both clinical and research perspectives, this study is by no means definitive. A first important limitation is the cross-sectional nature of the data collection. EB and IB have been considered as the outcomes, and IQ attachment and parenting as the risk factors, in line with most previous studies testing the cumulative effect 
hypothesis. Their status as outcomes or risk factors is open to discussion. Because data have been collected at the same time point, the current study only documents bidirectional relations among the variables rather than any causal pathway. Our study was explorative in nature and unlike previous studies more interested in the developmental process than in outcomes. Another important limitation in studies on adoption in general as well as in the current study is the lack of qualitative information about the individual care and nurturance that children actually received before adoption. In the absence of such information about the pre-adoption history, only group affiliation has been considered in the analyses. Thus all the adoptees have been considered as a homogeneous group. We were unable to take account of their individual history of institutionalization in the analysis for several reasons. First, the age of adoption is in most cases the only variable that is available. Although age of adoption may serve as a rough proxy for considering the effects of deprivation (see also van den Dries et al., 2009), it does not reveal the whole range of health and other forms of deprivation that may be part of the early lives of children prior to their adoption (Tan \& Marfo, 2006; Tan, Marfo, \& Dedrick, 2010). For this reason it is not a good indicator and should not be used alone. Second, the range and distribution of the age of adoption in our sample made it impossible to consider this unique information in line with the recent conclusions of the ERA study (Rutter \& Sonuga-Barke, 2010). This suggested that the age of adoption should not be treated as a continuous variable, but rather as a categorical one, with 6 months of age as a relevant cut-off point for distinguishing between those displaying no sequelae and those with substantial persisting deficits. In our sample however only 15 participants $(37.5 \%)$ were adopted before 6 months of age. A categorical treatment of the variable was therefore unfeasible. Future research should replicate our main finding, i.e. a positive answer to the core question "Is there a common pathway to behavioral maladjustment and scholastic failure for adopted and non-adopted adolescents?," in a larger and more homogeneous sample and with a longitudinal study design.

In conclusion, in a multi-informant study we tested the hypothesis of a common pathway to behavioral maladjustment and found several arguments for the existence of such a common pathway for adoptees and controls. The cumulative effect hypothesis was supported by the results. However, these provided a nuanced picture, leading to the conclusion that adoptees could benefit from treatment focusing on the cumulative effect of current individual and family risk factors, but that at the same time special attention needs to be paid to their risk of EB and comorbidity. Implications for research are that future studies should be more concerned with developmental processes than outcomes. Implications for policy and practice are that proposed prevention and treatment measures should not consider adopted adolescents very differently from their counterparts with regard to current adaptive or maladaptive pathways and that adopting parents should still be given specific support with providing a protective environment that can promote good behavioral adaptation in harmed children.

\section{References}

Achenbach, T. M., McConaughy, S. H., \& Howell, C. T. (1987). Child/adolescent behaviora and emotional problems: Implications of cross-informant correlations for situational specificity. Psychological Bulletin, 101, 213-232.

Achenbach, T. M., \& Rescorla, L. A. (2001). Manual for the ASEBA school-age forms and profiles. Burlington, VT: University of Vermont, Research Center for Children, Youth and Families.

Appleyard, K., Egeland, B., van Dulmen, M. H. M., \& Sroufe, L. A. (2005). When more is not better: The role of cumulative risk in child behavior outcomes. Journal of Child Psychology and Psychiatry, 46, 235-245.

Atzaba-Poria, N., Pike, A., \& Deater-Deckard, K. (2004). Do risk factors for problem behaviour act in a cumulative manner? An examination of ethnic minority and majority children through an ecological perspective. Journal of Child Psychology and Psychiatry, 45, 707-718.

Behen, M. E., Helder, E., Rothermel, R., Solomon, K., \& Chugani, H. T. (2008). Incidence of specific absolute neurocognitive impairment in globally intact children with histories of early severe deprivation. Child Neuropsychology, 14, 453-469.
Bimmel, N., Juffer, F., van Ijzendoorn, M. H., \& Bakermans-Kranenburg, M. J. (2003). Problem behavior of internationally adopted adolescents: A review and meta-analysis. Harvard Review of Psychiatry, 11, 64-77.

Brennan, K. A., Clark, C. L., \& Shaver, P. R. (1998). Self-report measurement of adult attachment: An integrative overview. In J. A. Simpson, \& W. S. Rholes (Eds.), Attachment theory and close relationships (pp. 46-76). New York, NY: Guilford Press.

Brodzinsky, D.M. (2011). Children's understanding of adoption: Developmental and clinical implications. Professional Psychology: Research and Practice, 42, 200-207.

Brodzinsky, D.M., Singer, L. M., \& Braff, A.M. (1984). Children's understanding of adoption. Child Development, 55, 869-878.

Christoffersen, M. N. (2012). A study of adopted children, their environment, and development: A systematic review. Adoption Quarterly, 15, 220-237.

Cicchetti, D., \& Rogosch, F. A. (1996). Equifinality and multifinality in developmental psychopathology. Development and Psychopathology, 8, 597-600.

Cohen, J. (Ed.). (1988). Statistical power analysis for the behavioral sciences (Second ed.) Hillsdale, NJ: Lawrence Erlbaum Associates.

Cole, D. A., \& Maxwell, S. E. (2003). Testing mediational models with longitudinal data: Questions and tips in the use of structural equation modeling. Journal of Abnormal Psychology, 112, 558-577.

Dalen, M., \& Rygvold, A. -L. (2006). Educational achievement in adopted children from China. Adoption Quarterly, 9, 45-58.

Dhavale, H. S., Bhagat, V., \& Thakkar, P. (2005). A comparative study of behaviour problems between adopted and nonadopted children in India. Journal of Child and Adolescent Mental Health, 17, 27-30.

Faul, F., Erdfelder, E., Buchner, A., \& Lang, A. G. (2009). Statistical power analyses using $G^{*}$ Power 3.1: Tests for correlation and regression analyses. Behavior Research Methods, 41, 1149-1160.

Faul, F., Erdfelder, E., Lang, A. G., \& Buchner, A. (2007). G* Power 3: A flexible statistical power analysis program for the social, behavioral, and biomedical sciences. Behavior Research Methods, 39, 175-191.

Fraley, R. C., Waller, N. G., \& Brennan, K. A. (2000). An item response theory analysis of self-report measures of adult attachment. Journal of Personality and Social Psychology, 78, 350-365.

Gagnon-Oosterwaal, N., Cossette, L., Smolla, N., Pomerleau, A., Malcuit, G., Chicoine, J. -F., et al. (2012a). Pre-adoption adversity and self-reported behavior problems in 7 year-old international adoptees. Child Psychiatry and Human Development, 43, 648-660.

Gagnon-Oosterwaal, N., Cossette, L., Smolla, N., Pomerleau, A., Malcuit, G., Chicoine, J. -F., et al. (2012b). Pre-adoption adversity, maternal stress, and behavior problems at school-age in international adoptees. Journal of Applied Developmental Psychology, 33, 236-242.

Gerard, J. M., \& Buehler, C. (2004). Cumulative environmental risk and youth problem behavior. Journal of Marriage and Family, 66, 702-720.

Goldman, G. D., \& Ryan, S. D. (2011). Direct and modifying influences of selected risk factors on children's pre-adoption functioning and post-adoption adjustment. Children and Youth Services Review, 33, 291-300.

Greenberg, M. T., Speltz, M. L., DeKlyen, M., \& Jones, K. (2001). Correlates of clinic referral for early conduct problems: Variable- and person-oriented approaches. Development and Psychopathology, 13, 255-276.

Hawk, B., \& McCall, R. B. (2010). CBCL behavior problems of post-institutionalized international adoptees. Clinical Child and Family Psychology Review, 13, 199-211.

Hjern, A., Lindblad, F., \& Vinnerljung, B. (2002). Suicide, psychiatric illness, and social maladjustment in intercountry adoptees in Sweden: A cohort study. The Lancet, 360, 443-448.

Hu, L., \& Bentler, P. M. (1999). Cutoff criteria for fit indexes in covariance structure analysis: Conventional criteria versus new alternatives. Structural Equation Modeling, 6, 1-55.

Judge, S. (2003). Determinants of parental stress in families adopting children from Eastern Europe. Family relations: An interdisciplinary journal of applied family studies, 52, $241-248$

Juffer, F., \& van IJzendoorn, M. H. (2005). Behavior problems and mental health referrals of international adoptees: A meta-analysis. JAMA: Journal of the American Medical Association, 293, 2501-2515.

Kendler, K. S., Sundquist, K., Ohlsson, H., Palmér, K., Maes, H., Winkleby, M.A., et al. (2012). Genetic and familial environmental influences on the risk for drug abuse: A national Swedish adoption study. JAMA Psychiatry, 69, 690-697.

Kreppner, J. M., O'Connor, T. G., Rutter, M., Beckett, C., Castle, J., Croft, C., et al. (2001). Can inattention/overactivity be an institutional deprivation syndrome? Journal of Abnormal Child Psychology: An official publication of the International Society for Research in Child and Adolescent Psychopathology, 29, 513-528.

Kriebel, D. K., \& Wentzel, K. (2011). Parenting as a moderator of cumulative risk for behavioral competence in adopted children. Adoption Quarterly, 14, 37-60.

Lanza, S. T., Rhodes, B.L., Nix, R. L., \& Greenberg, M. T. (2010). Modeling the interplay of multilevel risk factors for future academic and behavior problems: A personcentered approach. Development and Psychopathology, 22, 313-335.

Lindblad, F., Weitoft, G. R., \& Hjern, A. (2010). ADHD in international adoptees: A national cohort study. European Child \& Adolescent Psychiatry, 19, 37-44.

Lucio, R., Rapp-Paglicci, L., \& Rowe, W. (2011). Developing an additive risk model for predicting academic index: School factors and academic achievement. Child $\mathcal{E}^{\prime}$ Adolescent Social Work Journal, 28, 153-173.

McConaughy, S. H., \& Achenbach, T. M. (1994). Comorbidity of empirically based syndromes in matched general population and clinical samples. Journal of Child Psychology and Psychiatry, and Allied Disciplines, 35, 1141.

McConaughy, S. H., \& Skiba, R. (1994). Comorbidity of externalizing and internalizing problems. School Psychology Review, 22, 421-436.

Merz, E. C., \& McCall, R. B. (2010). Behavior problems in children adopted from psychosocially depriving institutions. Journal of Abnormal Child Psychology: An official publication of the International Society for Research in Child and Adolescent Psychopathology, 38, 459-470. 
Meunier, J. C., \& Roskam, I. (2007). Psychometric properties of a parental childrearing behavior scale for French-speaking parents, children, and adolescents. European Journal of Psychological Assessment, 23, 113-124.

Miller, L., Chan, W., Tirella, L., \& Perrin, E. (2009). Outcomes of children adopted from Eastern Europe. International Journal of Behavioral Development, 33, 289-298.

Noordhof, A., Oldehinkel, A. J., Verhulst, F. C., \& Ormel, J. (2008). Optimal use of multi-informant data on co-occurrence of internalizing and externalizing problems: The TRAILS study. International Journal of Methods in Psychiatric Research, 17, 174-183.

Oland, A. A., \& Shaw, D. S. (2005). Pure versus co-occurring externalizing and internalizing symptoms in children: The potential role of socio-developmental milestones. Clinical Child and Family Psychology Review, 8, 247-270.

Palacios, J., \& Brodzinsky, D. (2010). Adoption research: Trends, topics, outcomes. International Journal of Behavioral Development, 34, 270-284.

Palacios, J., Román, M., Moreno, C., \& León, E. (2009). Family context for emotional recovery in internationally adopted children. International Social Work, 52, 609-620.

Rescorla, L. A., Ginzburg, S., Achenbach, T. M., Ivanova, M. Y., Almqvist, F., Begovac, I., et al. (2013). Cross-informant agreement between parent-reported and adolescent self-reported problems in 25 societies. Journal of Clinical Child and Adolescent Psychology, 42, 262-273.

Rijk, C. H. A.M., Hoksbergen, R. A.C., ter Laak, J. J. F., van Dijkum, C., \& Robbroeckx, L. H. M. (2006). Parents who adopt deprived children have a difficult task. Adoption Quarterly, 9, 37-61.

Roskam, I., Meunier, J. C., Stievenart, M., \& Noël, M. -P. (2013). When there seem to be no predetermining factors: Early child and proximal family risk predicting externalizing behavior in young children incurring no distal family risk. Research in Developmental Disabilities, 34, 627-639.

Roskam, I., Stievenart, M., Tessier, R., Muntean, A., Escobar, M. J., Santelices, M. P., et al. (2014). Another way of thinking about ADHD: The predictive role of early attachment deprivation in adolescents' level of symptoms. Social Psychiatry and Psychiatric Epidemiology, 1-12.

Rutter, M., Beckett, C., Castle, J., Colvert, E., Kreppner, J., Mehta, M., et al. (2007). Effects of profound early institutional deprivation: An overview of findings from a UK longitudinal study of Romanian adoptees. European Journal of Developmental Psychology, 4, 332-350.

Rutter, M., Colvert, E., Kreppner, J., Beckett, C., Castle, J., Groothues, C., et al. (2007). Early adolescent outcomes for institutionally-deprived and non-deprived adoptees. I: Disinhibited attachment. Journal of Child Psychology and Psychiatry, $48,17-30$.

Rutter, M., \& Sonuga-Barke, E. J. (2010). Conclusions: Overview of findings from the ERA study, inferences, and research implications. Monographs of the Society for Research in Child Development, 75, 212-229.

Sánchez-Sandoval, Y., \& Palacios, J. (2012). Stress in adoptive parents of adolescents. Children and Youth Services Review, 34, 1283-1289.
Shaver, P. R., Mikulincer, M., \& Fraley, R. C. (2002). Attachment-related psychodynamics. Attachment \& human development (Print), 4, 133-161.

Sibley, C. G., \& Liu, J. H. (2004). Short-term temporal stability and factor structure of the revised experiences in close relationships (ECR-R) measure of adult attachment. Personality and individual differences, 36, 969-975.

Siira, V., Wahlberg, K. -E., Miettunen, J., Tienari, P., \& Làksy, K. (2006). Differentiation of adoptees at high versus low genetic risk for schizophrenia by adjusted MMPI indices. European Psychiatry, 21, 245-250.

Simmel, C., Brooks, D., Barth, R. P., \& Hinshaw, S. P. (2001). Externalizing symptomatology among adoptive youth: Prevalence and preadoption risk factors. Journal of Abnormal Child Psychology: An official publication of the International Society for Research in Child and Adolescent Psychopathology, 29, 57-69.

Sonuga-Barke, E., \& Rubia, K. (2008). Inattentive/overactive children with histories of profound institutional deprivation compared with standard ADHD cases: A brief report. Child: Care, Health and Development, 34, 596-602.

Tan, T. X., \& Marfo, K. (2006). Parental ratings of behavioral adjustment in two samples of adopted Chinese girls: Age-related versus socio-emotional correlates and predictors. Journal of Applied Developmental Psychology, 27, 14-30.

Tan, T. X., Marfo, K., \& Dedrick, R. F. (2010). Early developmental and psychosocial risks and longitudinal behavioral adjustment outcomes for preschool-age girls adopted from China. Journal of Applied Developmental Psychology, 31, 306-314.

Trentacosta, C. J., Hyde, L. W., Shaw, D. S., Dishion, T. J., Gardner, F., \& Wilson, M. (2008). The relations among cumulative risk, parenting, and behavior problems during early childhood. Journal of Child Psychology and Psychiatry, 49, 1211-1219.

van den Dries, L., Juffer, F., van Ijzendoorn, M. H., \& Bakermans-Kranenburg, M. J. (2009) Fostering security? A meta-analysis of attachment in adopted children. Children and Youth Services Review, 31, 410-421.

van der Vegt, E. J. M., Tieman, W., van der Ende, J., Ferdinand, R. F., Verhulst, F. C., \& Tiemeier, H. (2009). Impact of early childhood adversities on adult psychiatric disorders. Article. Social Psychiatry \& Psychiatric Epidemiology, 44, 724-731.

Wechsler, D. (2005). WISC-IV ECHELLE D'INTELLIGENCE.

Weinberg, R. A., Waldman, I., van Dulmen, M. H. M., \& Scarr, S. (2004). The Minnesota transracial adoption study: Parent reports of psychosocial adjustment at late adolescence. Adoption Quarterly, 8, 27-44.

Weiss, A. (1985). Symptomatology of adopted and nonadopted adolescents in a psychiatric hospital. Adolescence, 20, 763-774.

Whitten, K. L., \& Weaver, S. R. (2010). Adoptive family relationships and healthy adolescent development: A risk and resilience analysis. Adoption Quarterly, 13, 209-226.

Xing Tan, T., \& Marfo, K. (2006). Parental ratings of behavioral adjustment in two samples of adopted Chinese girls: Age-related versus socio-emotional correlates and predictors. Applied Developmental Psychology, 27, 14-30.

Zahn-Waxler, C., Klimes, D. B., \& Slattery, M. (2000). Internalizing problems of childhood and adolescence: Prospects, pitfalls, and progress in understanding the development of anxiety and depression. Development and Psychopathology, 12, 443-466. 